Article

\title{
Exploring Antecedents of Green Tourism Behaviors: A Case Study in Suburban Areas of Taipei, Taiwan
}

\author{
Judith Chen-Hsuan Cheng ${ }^{1}$, Ai-Hsuan Chiang ${ }^{2}$, Yulan Yuan ${ }^{3}$ and Ming-Yuan Huang ${ }^{4, *}$ \\ 1 Department of Applied Economics and Management, National Ilan University, Ilan City 26047, Taiwan; \\ chengch@niu.edu.tw \\ 2 Department of International Business, Ming Chuan University, Taipei 11103, Taiwan; eliot@mail.mcu.edu.tw \\ 3 Department of Landscape Architecture, Tunghai University, Taichung 40704, Taiwan; yoyoyuan@thu.edu.tw \\ 4 Department of Forestry and Natural Resources, National Chiayi University, Chiayi 60004, Taiwan \\ * Correspondence: myhuang@mail.ncyu.edu.tw; Tel.: +886-5-271-7518
}

Received: 26 April 2018; Accepted: 6 June 2018; Published: 8 June 2018

\begin{abstract}
Understanding user behaviors is the foundation to support the design and development of a sustainably built environment. This exploratory study used a mixed method to explore people's perception, motivation, intention, and behaviors of green tourism in Taiwan. The qualitative approach explored intrinsic and extrinsic factors that could influence people's intention to participate in green tourism. The quantitative approach provided evidence of influencing factors of green tourism. The findings suggested that variables, such as perception, attitudes, and self-efficacy, can indirectly influence green tourism behaviors through behavioral intention. This study suggests that government agencies should emphasize environmental education regarding the relationship between climate change and people's life; therefore, people will increase their environmental awareness regarding the urgent conditions of the environment, in addition to supporting green tourism and being more responsible for their tourism behaviors. For cities intending to accommodate tourism or Non-Governmental Organizations (NGOs) that are interested in promoting green tourism, it is critical to incorporate relevant factors, such as destination services and educational elements, into the design and development principles to built environment that supports green tourism activities.
\end{abstract}

Keywords: behavior; built environment; green tourism; intention; sustainability

\section{Introduction}

Over recent decades, global environmental change has been widely discussed, since many areas in the world are facing serious environmental problems. These problems are caused by industrial development, careless human behaviors, and unsustainable tourism behaviors. To help reduce these problems, every level, group, and society in the world should be involved in curbing these problems and the environmental design and planning for the tourism industry is no exception. Tourism activities directly and indirectly contribute to environmental issues because the use of airlines, tour buses, electricity, water, and many other resources requiring the consumption of natural resources and fossil fuels $[1,2]$. If the tourism industry continues to experience growth, it will exceed other industries and become the major source of global greenhouse gases (GHGs). To successfully achieve the reduction of GHGs, global policies, adopting environmentally friendly designs of the built environment, and a change in tourism travel behaviors are required. A number of international tourism organizations proposed their goals to reduce GHGs emissions. For example, the World Travel and Tourism Council [3] has used the $\mathrm{CO}_{2}$ emissions of 2005 as a base line and, specifically, identified emission reduction goals of $25 \%$ to $30 \%$ by 2020 and $50 \%$ by 2035 . The UK Department of Transport [4] identified sustainable low carbon travel in local areas. Some European countries and Australia have adopted methods 
to promote more sustainable travel programs for target populations [5]. Moreover, some studies have also suggested that people may decrease their intention to drive if the built environment can provide people with more alternatives to driving [6]. Based on the above discussion, tourism sectors and destination managers are aware of their responsibility to reduce carbon emission; therefore, the concept of green tourism has been promoted in many countries. To reduce the carbon emission resulting from the tourism industry, the Taiwan government has promoted green tourism in different regions. Various types of green tourism programs have been conducted in many counties in Taiwan [7]. The Green Tourism Association of Taiwan [8] defines green tourism as a travel mode that places an emphasis on people experiencing natural and cultural events, while leaving minimal carbon footprints and environmental impacts. Therefore, the main emphasis of green tourism is that energy consumption and $\mathrm{CO}_{2}$ emissions, caused by the activities, products, and services of tourism, should be minimized $[9,10]$. However, some of these green tourism programs are not sustainable due to a lack of tourist participation. In other words, tourists might be hesitant about partaking in green tourism when they need to deal with public transportation, facing greater inconveniences, and paying more expensive travel costs [11,12].

To design better environments for green tourism promotion, it is important to understand the factors that influence tourists' intentions to participate in green tourism. Numerous studies explore tourists' willingness to participate in environmentally friendly behaviors [13,14]. However, Dolnicar, Crouch, and Long [13] suggested that most of the behavioral studies focus on ecotourism or nature-based tourism sectors instead of the general public; they argue that researchers should use samples from the general public to explore these tourists' characteristics and needs. The understanding of these needs will enable destination managers and planners to modify the built environment to encourage tourists to engage in environmental friendly behaviors and allow tourism suppliers to use those built environments to provide appropriate services and programs in the future. As such, it is imperative to explore the general public's perceptions, attitudes, and their current green tourism behaviors, as well as the factors that influence the practice of these behaviors. Moreover, most of the studies on behavioral theories focus on internal factors, such as personal attitudes and self-efficacy, that influence people's decisions to perform environmentally friendly behaviors $[15,16]$ and rarely mention external factors, such as incentives or how the built environment can motivate people to execute certain environmental actions $[17,18]$. Therefore, it is imperative to investigate the external factors that could influence people's decisions concerning behaviors regarding green tourism. Based on the outlined reasons, the primary purpose of this study is to investigate the factors that influence people to participate in green tourism. The secondary purpose of this study is to explore how these factors influence people's intention to participate in green tourism. The third purpose of this research is to further explore factors that influence people's current green tourism behaviors.

First, we review the previous literature to form a basis for the investigation of possible factors that can predict tourists' intention and behaviors towards green tourism practices. We then use qualitative research methods to explore other factors that influence the general public's green tourism behaviors. Finally, we conduct quantitative measurement to explore the associations among green tourism behaviors and other factors.

\section{Literature Review}

In this section, we first reviewed the association between motivation and environmental behavior, followed by knowledge, perception, and environmental behaviors, and, lastly, attitudes, efficacy, intention, and environmental behaviors. The literature review explores the possible factors that could influence people's green tourism behaviors.

\subsection{Motivation and Environmental Behaviors}

Studies investigating motivation have long been a topic of interest in tourism and travel research. Motivation indicates people's psychological/biological needs and wants that can influence their 
decision-making $[19,20]$. Kasser and Ryan [21] described two types of motivation, which are intrinsic and extrinsic. Intrinsic motivation associates with internal feelings and instincts, such as the value or attitude toward actions, while extrinsic motivation relates to external reinforcement or social recognition, such as gaining benefits [21,22]. Previous studies showed that intrinsic motivation is a promising factor to guide environmental attitudes [23], as well as environmentally responsible behaviors $[22,24,25]$. This study aims to investigate the motivations that trigger people's intention to participate in green tourism behaviors. We hope to identify intrinsic and extrinsic motivations of green tourism behaviors to help providers of green tourism to understand people's needs, in addition to providing appropriate green tourism programs in the future. Therefore, we propose Hypothesis 1.

Hypothesis 1 (H1). Motivation can positively influence people's behavior through behavioral intention.

\subsection{Knowledge, Perception, and Environmental Behaviors}

Knowledge is thought to be the antecedent variable of behaviors and researchers have identified its direct and indirect influences on pro-environmental behaviors [16,26-28]. In environmental education, numerous researchers have indicated that knowledge is associated with conservation behavior $[26,28]$. Boubonari et al. [29] studied school teachers' knowledge, attitude, and behaviors regarding marine pollution and their findings suggested that knowledge is positively correlated with attitudes and behaviors, with the knowledge-attitude link being stronger than the knowledge-behavior link. Other researchers have identified a causal relationship between knowledge and behavior. For example, Frick, Kaiser, and Wilson [27] suggest that action-related knowledge and effectiveness knowledge (which addresses the relative effectiveness of conservation actions) have a direct effect on individuals' behavioral performance. Cheng and Monroe [16] studied children's affective attitudes toward nature and found that environmental knowledge has direct effects on children's affective attitudes, which can, in turn, influence their interests in environmentally friendly practices. Similarly, Carmi et al. [30] found that environmental knowledge can indirectly drive pro-environmental behaviors through environmental emotions. Based on the evidence of the discussed studies, environmental knowledge is a factor that is associated with the development of pro-environmental behaviors. As a result, we propose Hypothesis 2 and Hypothesis 3.

Hypothesis 2 (H2). People's perception of sustainability can positively influence their attitudes toward green tourism

Hypothesis 3 (H3). People's perception of green tourism can have a positive influence on their attitudes toward green tourism.

\subsection{Attitudes, Efficacy, Intention, and Environmental Behaviors}

Many researchers have explored pro-environmental behaviors to provide insights that explain, predict, and develop these behaviors [15,31-34]. Various theories have demonstrated the associations among social norms, values, attitudes, behavioral intentions, and actual behaviors [15,33,35]. These attitudes and behaviors are likely formed over time and it is possible to nurture these attitudes with environmental education programs. If programs promote environmental attitudes about behaviors, they may also succeed in increasing the intentions to perform these behaviors.

The theory of planned behavior is a classic framework that explains the relationship between predictive variables and behaviors [15]. The theory is composed of five basic concepts: Attitude toward the behavior, subjective norm, perceived behavioral control, intentions, and actual behavior, and suggests that a person's intention to perform a behavior is the direct determinant of the action. A person's intention is a function of three basic personal factors: Attitude toward the behavior, 
which determines a person's positive or negative evaluation of performing the behavior; subjective norm, which is a person's perception of the social pressures put on him/her to perform or not perform the behavior; and perceived behavioral control, which is a person's perception of his/her ability to perform a particular behavior. Eagly and Chaiken [36] indicated that attitude is a person's psychological inclination towards a particular entity. Numerous attitudinal studies have showed a positive relationship between environmental attitudes and behaviors. For example, studies suggest that pro-environmental attitudes were positively influential on people's willingness to pay $[37,38]$. Ajzen [15] indicated that perceived control is a similar form to measure one's capability to perform a certain action. Self-efficacy is considered to be an important predictor of environmentally responsible behaviors. Wood and Bandura [39] (p. 408) defined self-efficacy as the belief in one's own capacity to organize and guide the courses of action required to tackle certain situations in the immediate future. Previous studies have suggested that self-efficacy directly and indirectly influences residents' recycling behaviors in Spain [22]; self-efficacy strongly influences children's affective attitudes, as well as their intention to practice environmentally responsible behaviors [16]. The theory of plan behavior also suggests that intention can best predict a behavioral achievement. Therefore, we propose Hypothesis 4, Hypothesis 5 and Hypothesis 6.

Hypothesis 4 (H4). People's attitudes towards green tourism can positively influence their intentions of participating in green tourism

Hypothesis 5 (H5). People's self-efficacy can have a positive impact on their intentions of participating in green tourism

Hypothesis 6 (H6). People's intention of participating in green tourism can positively influence their environmentally responsible green tourism behaviors.

\subsection{External Factors and Travel Behaviors}

Some researchers have investigated the associations between the built environment and people's behaviors in residential areas. Handy, Cao, and Mokhtarian [6] studied the relationship between the built environment and travel behavior in the United States. Their finding demonstrated that, if residents were closer to their destinations and were provided with alterative travel modes, driving decreased. The results implied that the design of the built environment is influential on travel patterns in a given destination. Similarly, Titze, Stronegger, Janschitz, and Oja [18] explored the factors that influence people to use bicycles as their transportation mode in Austria. Their findings suggested that the condition of the physical environment can influence people's intention to bike. Based on the conclusions from the discussed studies, people tended to change their behaviors if there were appropriate designs. Therefore, this implied that the involvement of transportation and destination planners is critical during the planning stages of green tourism programs. Moreover, other studies suggested that nature-based recreation experiences could positively influence tourists' environmental attitudes, which further influences tourists' environmentally responsible behaviors. It is suggested that, if service providers can maintain destinations to high standards and provide positive experiences for tourists, tourists can, thus, develop positive environmental attitudes and behaviors and further contribute to the sustainable tourism industry [40].

The discussed studies present the theoretical background of factors that could influence behavioral intention and environmental behaviors. However, this study would like to examine whether there are other factors that could influence the general public's intention to participate in green tourism. Therefore, Study 1, presented hereafter, used a qualitative approach to explore motivations (both intrinsic and extrinsic factors) that could influence tourists; behavioral intentions regarding green tourism participation. Followed by Study 2, which uses a quantitative approach to explore how antecedent variables of green tourism participation influence people's green tourism behaviors. 


\section{Study 1}

The researchers concluded that there was an insufficient understanding of factors that influence people's green tourism behaviors; therefore, it was necessary to perform an exploratory qualitative study to establish quantitative instruments that could be tested later in the quantitative stage. The specific research question for the qualitative initiative was: What are people's motivations to practice green tourism behaviors?

\subsection{Study Area and Participants}

The researchers selected the top five popular tourism sites that can be accessed by public transportation in New Taipei City, which are Tamsui, Jiufen, Houtung, Yingge, and Sanxia (Figure 1). The participants were 18 years or older and had travelled to these areas between March and April of 2013.

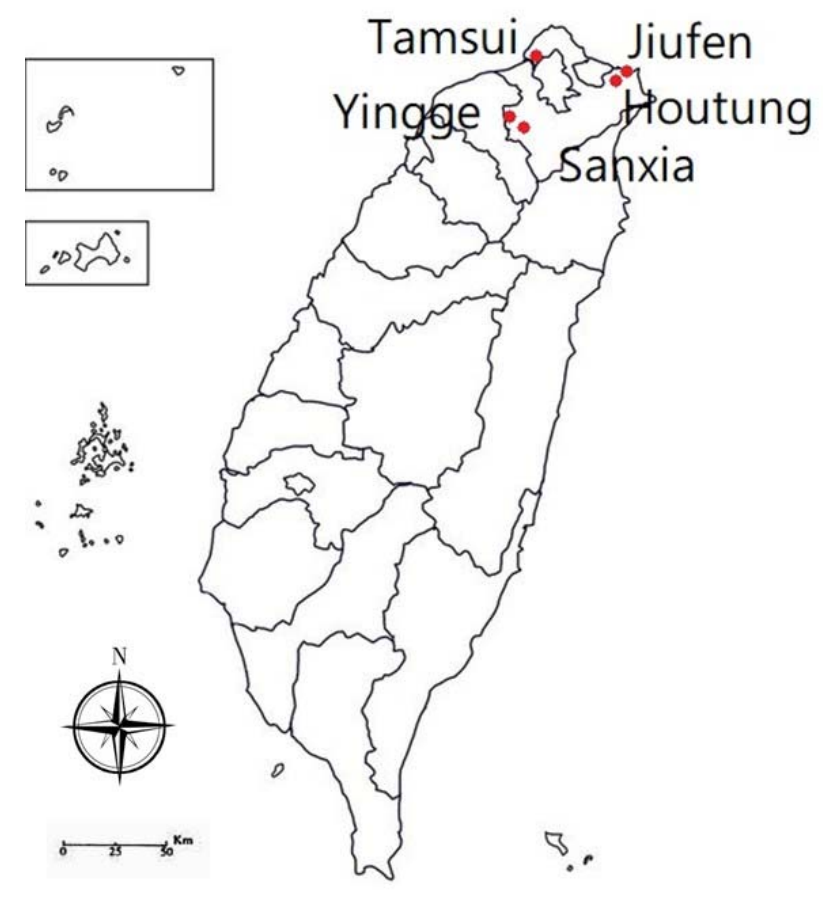

Figure 1. Interview sites.

\subsection{Qualitative Initiative}

During the first stage of the research, we used semi-structured interviews as the main technique to collect qualitative data. Convenience sampling was used to interview visitors. The interviewer selected the participants based on their availability. Each available participant was approached one at a time and he or she was asked of their willingness to be a research participant. After the interview with one participant was completed, the interviewer approached the next available participant. Before the interview, the researchers described the meaning of green tourism to the participants, and researchers used open-ended questions to explore the factors that could influence people's willingness of their participation in green tourism programs. The interview questions were: "Have you ever heard about green tourism?" and "What factors can influence your decision to participate in green tourism programs?" Each interview took about 8 to 10 min until the participants could not describe any new concepts. 


\subsection{Data Analysis}

After the researchers approached 35 tourists, the data seemed saturated; therefore, we stopped the qualitative data collection. Each interview was transcribed and two researchers used Strauss and Corbin's [41] three coding steps, including open coding, axial coding, and selective coding, to explore factors that influence people's willingness to participate in green tourism.

\subsection{Results}

After combining items that have similar meanings and modifying the wording, two major types of factors were generated, including extrinsic factors and intrinsic factors, which are listed in Table 1.

Regarding extrinsic factors, many respondents identified an economic influence, as well as the availability of green alternatives at the destination. Some of the comments by participants were quoted below:

It is important to have convenient public transportation. If the public transportation is not convenient or available, it is hard for people to participate in green tourism. (C6)

If there is public transportation available between different destinations, I will take it because it is convenient. (D2)

Table 1. Factors that influence green tourism participation.

\begin{tabular}{lll}
\hline Selective Code & Axial Code & Description (Open Code) \\
\hline \multirow{3}{*}{ Extrinsic factors } & Economic influence & Reasonable travel costs (27) \\
\cline { 2 - 3 } & Destination built environment & $\begin{array}{l}\text { Convenient public transportation (23) } \\
\text { Prevalence of environmental friendly hotels (9) }\end{array}$ \\
\cline { 2 - 3 } & Destination experiences & $\begin{array}{l}\text { The program should be interesting and attractive (16) } \\
\text { Be close to the local environment (15) } \\
\text { Destinations should have professional guided-services (9) } \\
\text { To experience high quality interpretation (4) }\end{array}$ \\
\hline \multirow{2}{*}{ Intrinsic factors } & Tocial factors & $\begin{array}{l}\text { To be with family and friends (10) } \\
\text { To know people who have similar values and interests (4) }\end{array}$ \\
\cline { 2 - 3 } & \multirow{3}{*}{ Self-fulfilment factors } & $\begin{array}{l}\text { To try different types of tourism programs (11) } \\
\text { Having environmental responsibility (8) } \\
\text { Having environmental awareness (6) } \\
\text { To learn new carbon reduction knowledge (5) }\end{array}$ \\
\end{tabular}

The participants' comments suggested that not only the availability, but also the convenience, of public transportation is critical for people to participate in green tourism. This is similar to a study presented by Larsen and Guiver [42], which reports that change towards more sustainable tourism mobility is likely to happen if tourists can value experiences at closer destinations with more available sustainable transportation.

Other respondents described the availability of environmental friendly hotels:

If there are more green/environmental friendly hotels available, we are more likely to choose those types of hotels. (C2)

The above ideas indicate that, to promote green tourism, destinations should have sufficient facilities that could accommodate the ideas of carbon reduction. Other than destination facilities, respondents also spoke about their expectations of green tourism experiences. Their comments were as follows:

I like traveling a lot, so if there are attractive green tourism programs or activities, I will

likely participate. (A2) 
Different tourism sectors are very competitive. If you want people to participate in green tourism, the activities must be very interesting and attractive. (A4)

I care a lot about professional guiding services, since I like to learn in-depth knowledge in the destinations. (A1)

The above quotes illustrate that, if the destinations can provide relevant services or experiences that are interesting to the visitors, people will be willing to participate in green tourism. This describes the extrinsic motivation of green tourism.

In addition to extrinsic factors, several respondents explained their motivation to participate in green tourism based on experiential factors. Some of them talked about their previous experiences. For example, one participant mentioned:

I went to I-Lan for a green tourism program. We biked around the rice field, and had a series of in-depth environmental interpretation. The experience was memorable and interesting, so I will like to have similar experience again in the future. (C3)

From this participant, we found that experience was an important factor to attract tourists. Tourism sectors can provide memorable green tourism experiences to satisfy people. The above finding also implied that, if people have more environmental experiences, they would be more likely to participate in green tourism. Another finding was that tourists' own environmental awareness could motivate them to participate in green tourism. Some respondents pointed out:

I am sensitive to environmental issues, so if there is a green tourism program available, I will like to participate. (A1)

People who have interests to learn about the environment or who are having environmental responsibility will participate in these types of programs. (D2)

\subsection{Discussion}

We explored the factors that influence people's intentions to participate in green tourism. We found that both intrinsic and extrinsic factors can motivate people to participate in green tourism. To design and promote green tourism activities in a more effective way in the future, understanding the influential factors of green tourism behaviors is imperative. Therefore, the results of the qualitative study were used to develop a scale to reach a more general public and investigate the important factors that can influence people's willingness to participate in green tourism. Thirteen items were designed, and are listed in Table 2, based on the qualitative findings to represent intrinsic and extrinsic factors that motivate people to participate in green tourism.

Table 2. Factors that motivate people to participate in green tourism.

\begin{tabular}{c}
\hline Items \\
\hline Learning new ways of environmental conservation \\
Helping with environmental protection \\
Promotion of low carbon tourism \\
Awareness of environmental conservation \\
A skillful low carbon local tour guide \\
Professional low carbon guiding services \\
Convenient public transportation services \\
Attractive green tourism programs \\
Prevalence of green hotels \\
Reasonable travel cost in the destination \\
Diverse local cultural features \\
Experiencing different types of tourism \\
Leaving the crowed city environment
\end{tabular}




\section{Study 2}

The aim of Study 2 was to understand the predictors of green tourism intention and behaviors. The predictors include factors that are identified in literature review and were explored in the qualitative study. The research questions include: Can people's intention of participation in green tourism influence green tourism behaviors? Can perception, attitudes, self-efficacy, and other factors influence people's intentions to participate in green tourism?

The quantitative questionnaire included nine major sections. Section 1 included four questions that measured people's perception of sustainability. Section 2 included six questions that explored people's perceptions of green tourism. Section 3 was composed of four questions that measured people's self-efficacy, with statements such as, "I can reduce environmental impacts through participation in green tourism." Section 4 was composed of five questions that measured people's attitudes toward green tourism behaviors, with statements such as, "Green tourism can ensure the quality of the environment." Section 5 included 13 questions measuring factors that can influence people's willingness to participate in green tourism, which were developed from the qualitative study. Section 6 included one question measuring tourists' willingness to participate in green tourism in the future. The statement was, "I will follow green tourism principles when I am traveling". Section 7 included five questions that were designed following the Carbon Reduction Tourism principals provided by the Environmental Protection Agency (EPA) [43] in Taiwan. The rules included: People who participate in carbon reduction tourism should limit their footprint from transportation; they should carry light personal belongings; they should consume the local and seasonal food; they should leave no trace, etc." The example statement was, "I choose to take public transportation if available." All constructs were measured by using a 5-point Likert scale from 1, being strongly disagree, to 5, being strongly agree. The last section of the questionnaire was demographic information. Then the questionnaire was pilot tested with 60 participants to investigate the question wording and reliability. Two items from the perception of green tourism, "The carbon emission of different types of hotels is different" and "Taking public transportation can reduce carbon emission", were eliminated due to low reliability. The questionnaire items are translated in Appendix A.

\subsection{Data Collection}

Survey data were collected in the same five locations as visitor interviews were collected. The self-administrated questionnaire was handed to the participants. Each questionnaire took about $10 \mathrm{~min}$ to finish. Data were collected during June to August 2013. The study distributed 450 questionnaires and 53 were eliminated due to missing data, which left 397 surveys for data analysis.

\subsection{Data Analysis}

Upon completion of the data collection, data were analyzed using SPSS 20.0. Among the 397 effective samples, about $45 \%$ were men and $55 \%$ were women. The majority $(78 \%)$ of tourists were from Northern Taiwan. The age distribution was $41 \%$ (20-29 years), 33\% (30-39 years), 17\% (40-49 years), $6 \%$ (50-59 years), and 3\% (above 60 years). About $60 \%$ of visitors had a degree in college, followed by high school (19\%), technical school (17\%), and secondary level education $(2.8 \%)$. Then data were analyzed using exploratory factor analysis to investigate factors that could predict the willingness of green tourism participation. Following the factor analysis, multiple regressions analysis was applied to discover the predictors of visitors' willingness to participate in carbon reduction tourism.

Factor analysis was used to explore the components of people's willingness to participate in green tourism behaviors. Thirteen items were factor analyzed. Researchers used the Kaiser-Meyer-Olkin (KMO) Measure of Sampling Adequacy to evaluate the appropriateness of the factor analysis. The results showed KMO $=0.72$ (Barlett's test of sphericity $=1334.51, p<0.01$ ), which allowed us to further assess factor analysis. Two items with factor loading lower than 0.4 were eliminated [44], which left 11 items for the final data analysis. Three major categories were generated to represent 
factors that influence people to participate in green tourism behaviors: Self-environmental awareness, destination services/features, and professional interpretation (Table 3). Self-environmental awareness belongs to intrinsic motivation, while destination green service and professional interpretation belongs to extrinsic motivation.

Table 3. Motivation of green tourism participation.

\begin{tabular}{lccc}
\hline \multicolumn{1}{c}{ Statements } & $\begin{array}{c}\text { Self-Environmental } \\
\text { Awareness }\end{array}$ & $\begin{array}{c}\text { Destination Green } \\
\text { Services }\end{array}$ & $\begin{array}{c}\text { Professional } \\
\text { Interpretation }\end{array}$ \\
\hline Learning new ways of environmental conservation & 0.85 & & \\
Helping with environmental protection & 0.78 & & \\
Promotion of low carbon tourism & 0.75 & & \\
Awareness of environmental conservation & 0.66 & 0.76 & \\
Convenient public transportation services & & 0.75 & \\
Attractive green tourism program & & 0.60 & \\
Prevalence of green hotels & & 0.55 & 0.91 \\
Diverse local culture and features & & 0.41 & 0.90 \\
Reasonable travel costs in the destination & 3.28 & & 1.40 \\
Skillful low carbon local tour guide & 24.26 & 1.86 & 59.41 \\
Professional low carbon guiding services & 24.26 & 18.29 & 0.63 \\
Eigen values & 0.78 & 42.55 & \\
Percentage of variance explained & & 0.87 & \\
Cumulative variance explained & & & \\
Cronbach's alpha & & & \\
\hline
\end{tabular}

\subsection{Testing of Hypotheses}

After factors analysis, motivation of green tourism participation was categorized into three factors; therefore, the previous Hypothesis 1, was modified to Hypothesis 1a, Hypothesis $1 \mathrm{~b}$ and H1c. Professional interpretation can influence people's intention of participating in green tourism. The hypothetical model of this study is explained in Figure 2. The study used the statistical package, Statistical Product and Service Solutions (SPSS), as well as Analysis of MOment Structure (AMOS), as our data analysis tool and a $95 \%$ of confidence level was implemented for the statistical analysis.

Hypothesis 1a (H1a). Self-environmental awareness can positively influence people's intention of participating in green tourism.

Hypothesis $1 \mathbf{b} \mathbf{~ ( H 1 b ) . ~ D e s t i n a t i o n ~ g r e e n ~ s e r v i c e ~ c a n ~ p o s i t i v e l y ~ i n f l u e n c e ~ p e o p l e ' s ~ i n t e n t i o n ~ o f ~ p a r t i c i p a t i n g ~ i n ~}$ green tourism.

Hypothesis 1c (H1c). Professional interpretation can influence people's intention of participating in green tourism.

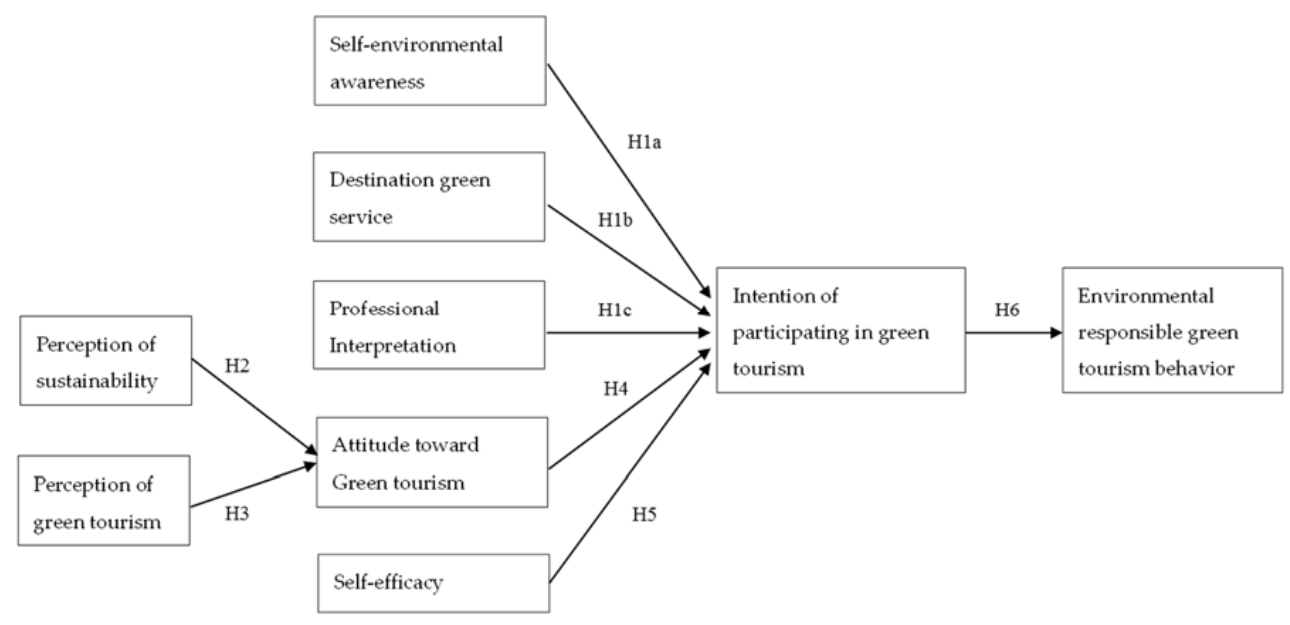

Figure 2. Proposed model of green tourism behaviors. 


\subsection{Results}

The results were divided into two parts: The analyses of reliability and validity, and hypotheses testing. The following section shows the reliability and validity, as well as whether the results support our research hypotheses.

\subsubsection{Reliability and Validity}

A series of analyses were performed to test the reliability and validity of the constructs. Table 4 summarizes the descriptive statistics of the study variables. All correlations are significant at the 0.05 significance level. Besides, composite reliabilities are in italics in the diagonal. For composite reliabilities, a minimum value of 0.7 is considered acceptable.

The study also used confirmatory factor analysis (CFA) to test our measurement model. The fit indices of CFA were: $\chi^{2} / \mathrm{df}=2.685 ; \mathrm{NNFI}=0.801 ; \mathrm{CFI}=0.826 ;$ AGFI $=0.810$; $\mathrm{SRMR}=0.066$; RMSEA $=0.065$. Therefore, our research model is acceptable, indicating convergent validity [45]. The confirmatory factor analysis confirmed if the items belong to the constructs. The results demonstrate construct unidimensionality.

The study examined discriminant validity among constructs using a procedure provided by Fornell and Larcker [46], whose criterion for discriminant validity is that the variance shared by a construct with its indicators should be greater than the variance shared with other constructs in the model. As shown in Table 4, the square root of the average variance extracted (ranging from 0.574 to 0.893 ) was greater than almost all of the corresponding correlations, indicating adequate discriminant validity.

The diagonal values in italics to the right of the slash are the square root of the average variance extracted (AVE) for each construct; the values to the left are the composite reliabilities. 
Table 4. Descriptive statistics and correlations.

\begin{tabular}{|c|c|c|c|c|c|c|c|c|c|c|}
\hline Variables & Mean (SD) & 1 & 2 & 3 & 4 & 5 & 6 & 7 & 8 & 9 \\
\hline 1. Perception of sustainability & $\begin{array}{c}3.095 \\
(0.790)\end{array}$ & \multicolumn{2}{|c|}{$0.691 / 0.631$} & & & & & & & \\
\hline 2. Perception of green tourism & $\begin{array}{c}3.761 \\
(0.699)\end{array}$ & $0.314^{* *}$ & \multicolumn{2}{|c|}{$0.801 / 0.681$} & & & & & & \\
\hline 3. Attitudes toward green tourism & $\begin{array}{c}3.695 \\
(0.549)\end{array}$ & 0.133 ** & $0.388^{* *}$ & \multicolumn{2}{|c|}{$0.778 / 0.574$} & & & & & \\
\hline 4. Self-efficacy & $\begin{array}{c}3.386 \\
(0.750)\end{array}$ & $0.126^{*}$ & $0.404^{* *}$ & $0.528 * *$ & \multicolumn{2}{|c|}{$0.693 / 0.644$} & & & & \\
\hline 5. Self-environmental awareness & $\begin{array}{c}3.426 \\
(0.691)\end{array}$ & 0.180 ** & $0.299 * *$ & $0.463^{* *}$ & $0.381^{* *}$ & \multicolumn{2}{|c|}{$0.834 / 0.711$} & & & \\
\hline 6. Destination green service & $\begin{array}{c}3.864 \\
(0.619)\end{array}$ & $0.124^{*}$ & $0.126^{*}$ & $0.218 * *$ & $0.302 * *$ & $0.327^{* *}$ & \multicolumn{2}{|c|}{$0.703 / 0.589$} & & \\
\hline 7. Professional interpretation & $\begin{array}{c}3.731 \\
(0.855)\end{array}$ & 0.048 & 0.025 & 0.071 & 0.056 & $0.283^{* *}$ & 0.061 & \multicolumn{2}{|c|}{$0.896 / 0.893$} & \\
\hline 8. Intention of participating in green tourism & $\begin{array}{c}3.496 \\
(0.855)\end{array}$ & 0.131 ** & $0.291 * *$ & $0325 * *$ & $0.271^{* *}$ & $0.378 * *$ & 0.303 ** & $0.175^{* *}$ & $-/-$ & \\
\hline 9. Environmental responsible green tourism behavior & $\begin{array}{c}2.904 \\
(0.699)\end{array}$ & 0.339 ** & $0.365^{* *}$ & $0.379 * *$ & $0.449^{* *}$ & $0.482 * *$ & 0.241 ** & $0.121 *$ & $0.268^{* *}$ & $0.748 / 0.611$ \\
\hline
\end{tabular}

Note: $N=398 .{ }^{*}$ Correlations at the 0.05 significant level, ${ }^{* *}$ Correlations at the 0.01 significant level. 


\subsubsection{Hypotheses Testing}

Table 5 presents the AMOS estimates for our propose model. The fit indices for the proposed model were: $\chi^{2}=1257.926(\mathrm{df}=441 ; p<0.001)$; NNFI $=0.774, \mathrm{CFI}=0.799 ; \mathrm{AGFI}=0.797$, $\mathrm{SRMR}=0.081$; RMSEA $=0.068$. The fit indices suggest that the data fit our model well. The results reveal that environmental self-awareness significantly impacted on intentions of participating in green tourism ( $\beta=0.254, p<0.001)$. Meanwhile, destination green services are also significantly related to intentions of participating in green tourism $(\beta=0.155, p<0.001)$. However, the results do not support the hypothesis that professional interpretation is positively related to intentions of participating in green tourism $(\beta=0.035, p>0.05)$. Furthermore, the results show that perceptions of sustainability are not significantly related to attitudes toward green tourism $(\beta=-0.021, p>0.05)$. The results confirm that perceptions of green tourism are significantly related to attitudes toward green tourism ( $\beta=0.443, p<0.001$ ). The results reveal that attitudes toward green tourism are significantly related to intentions of participating in green tourism $(\beta=0.169, p<0.05)$. The results support the conclusion that self-efficacy is significantly related to intentions of participating in green tourism $(\beta=0.307, p<0.001)$. Moreover, the results confirm that intentions of participating in green tourism significantly impacts on environmentally responsible green tourism behavior $(\beta=0.966, p<0.001)$.

Table 5. Path estimates for the hypothesized model.

\begin{tabular}{lc}
\hline \multicolumn{1}{c}{ Path } & Path Estimates \\
\hline H1a: Environmental self- awareness $\rightarrow$ Intentions of participating in green tourism & $0.254 * * *$ \\
H1b: Destination green service $\rightarrow$ Intentions of participating in green tourism & $0.155 * * *$ \\
H1c: Professional interpretation $\rightarrow$ Intentions of participating in green tourism & 0.035 \\
H2: Perception of sustainability $\rightarrow$ Attitudes toward green tourism & -0.021 \\
H3: Perception of green tourism $\rightarrow$ Attitudes toward green tourism & $0.443 * *$ \\
H4: Attitudes toward green tourism $\rightarrow$ Intentions of participating in green tourism & $0.169 *$ \\
H5: Self-efficacy $\rightarrow$ Intentions of participating in green tourism & $0.307 * * *$ \\
H6: Intentions of participating in green tourism $\rightarrow$ Environmentally responsible tourism behavior & $0.966 * * *$ \\
\hline Note: $* p<0.05, * * * p<0.001$. The fit indices: $\chi^{2} / \mathrm{df}=2.852 ;$ NNFI $=0.774$, CFI $=0.799 ;$ AGFI $=0.797$, SRMR $=0.081 ;$ \\
RMSEA $=0.068$.
\end{tabular}

After hypotheses testing, we have several major findings. First, the perception of green tourism can significantly predict attitudes toward green tourism. Second, attitudes toward green tourism, self-efficacy, self-environmental awareness, and destination services can significantly predict intentions of participating in green tourism. Third, intentions of participating in green tourism can significantly predict environmentally responsible tourism behaviors.

\subsection{Discussion}

This study used both factors that were identified from the literature and the factors generated from qualitative results to predict people's willingness to participate in green tourism. Our study explored people's actual tourism behaviors and found that people who have stronger intentions to participate in green tourism are more likely to perform environmentally responsible travel behaviors. This finding is consistent with previous studies that intention is one of the strongest predictors of behaviors $[15,47]$. Also consistent with previous literature, perception, attitudes, and self -efficacy are also predictors of behavioral intentions $[15,16,39]$.

One interesting finding of our study is that destination services, which is an external factor, can significantly influence people's intention to participate in green tourism. While previous literature has focused on people's internal motives of performing certain behaviors, our study explained that external factors can play an important role for people to perform certain behaviors. One possible explanation is that, if the destinations are attractive and have services that can be convenient or easy to use, people will be more willing to participate in green tourism, which is similar to previous suggestions in the literature, which indicate that external factors, such as economic, social, and cultural, and design 
of the built environment might influence people's behavioral decisions $[6,17,18,28]$. However, we further investigated the predictability of other independent variables of people's willingness to participate in green tourism programs and found that professional interpretation is not a significant predictor. The reason may be because people who want to participate in green tourism programs are more interested in local resources rather than professional guides and interpretation services.

\section{Conclusions and Implications}

This exploratory study used both qualitative and quantitative methods to find out factors that can influence people's willingness to participate in green tourism, as well as the factors that influence people's responsible green tourism behaviors. The findings show that people's own environmental awareness and destination services are influential on people's willingness to participate in green tourism. These findings provide suggestions for government agencies, tourism sectors, NGOs, and city planners and developers that want to promote green tourism programs in the future. We suggest that government agencies should emphasize environmental education regarding the relationships between climate change and people's lives; in doing so, people will increase their environmental awareness regarding the urgent conditions of the environment and will support green tourism efforts, as well as being more responsible in their tourism behaviors. For the tourism sectors or NGOs that are interested in promoting green tourism, it is critical to consider factors, such as destination services and educational elements, during the program developmental process, since our findings suggest that, if the destination can provide more green tourism services, people are more likely to participate in green tourism in the future. We also suggest that city planners and developers provide opportunities for public involvement and consider environmentally friendly designs during their planning processes so that they will know the actual demands for the users. For example, different stakeholders are able to participate in the planning stage and make it possible to have more convenient public transportation for green tourism promotion.

The quantitative results suggested that self-environmental awareness, self-efficacy, and destination services, as well as their attitudes toward green tourism, are critical factors for people to make decisions about participating in green tourism. The results are consistent with previous studies, which indicate that both intrinsic and extrinsic motivations were associated with environmental behaviors [48,49]. We suggest future research should use more in-depth qualitative research methods to explore people's motivations and thoughts regarding green tourism participation; therefore, countries that want to promote green tourism may benefit from these findings. This study was conducted in sub-urban areas in Taiwan, and, thus, we also suggest researchers should explore how these factors influence people to participate in green tourism programs in different cultures and countries. More diverse data could be beneficial for green tourism promotion all over the world.

\section{Limitations}

This study has several contextual and design limitations that may affect the results. The qualitative study used convenient sampling on site. Although, after interviewing 35 people, the data had been saturated, on-site interviews may have several limitations. First, people do not have a large period of time to explain their thoughts. Second, people do not have detailed ideas regarding green tourism so their responses may be limited. Therefore, we suggest further in-depth interviews can be conducted to explore the factors that influence people's decision to participate in green tourism programs. Third, this study investigated the general public's green tourism behaviors; some participants might not have in depth knowledge regarding green tourism, which might result in scoring low in the actual green tourism behaviors. A more precise questionnaire can be designed to investigate green tourism participants in the future. 
Author Contributions: J.C.-H.C. led coordinated the research; M.-Y. Huang and Y.Y. reviewed relevant literatures and developed implications; J.C.-H.C. and A.-H.C. analyzed the data; All Authors contributed to the manuscript preparation.

Acknowledgments: The research is funded by the Ministry of Science and Technology, Taiwan, R.O.C. under Grant No. NSC 100-2511-S-032-005-MY2. The authors would like to thank for the former research assistant Ming-Hsun Yeh for helping to conduct the research and the funding support from National Science Council in Taiwan.

Conflicts of Interest: The authors declare no conflict of interest.

\section{Appendix A}

\begin{tabular}{|c|c|c|}
\hline Section 1: Perception of sustainability & Mean & SD \\
\hline I understand carbon footprint & 2.86 & 1.17 \\
\hline I understand carbon cycle & 2.77 & 1.15 \\
\hline I understand green consumption & 3.14 & 1.01 \\
\hline I understand sustainable development & 3.61 & 0.96 \\
\hline \multicolumn{3}{|l|}{ Section 2: Perception of green tourism } \\
\hline Consuming local food helps reduce carbon emission & 3.61 & 1.01 \\
\hline Reducing use of disposable products helps reduce carbon emission & 3.93 & 0.83 \\
\hline Wearing lightweight clothing helps reduce carbon emission & 3.60 & 0.91 \\
\hline Carrying your own toothbrush and towels helps reduce carbon emission & 3.89 & 0.89 \\
\hline Taking public transportation can reduce carbon emission & 4.01 & 0.82 \\
\hline The carbon emission of different types of hotels is different & 3.90 & 0.73 \\
\hline \multicolumn{3}{|l|}{ Section 3: Self-efficacy } \\
\hline I can reduce environmental impacts through participation in green tourism & 3.74 & 0.89 \\
\hline I have a responsibility to reduce carbon emission during my travel journey & 3.35 & 0.94 \\
\hline I have a responsibility to persuade those who are damaging natural resources & 3.08 & 1.07 \\
\hline Carbon emission reduction from green tourism cannot be neglected & 3.55 & 1.05 \\
\hline \multicolumn{3}{|l|}{ Section 4: Attitudes toward green tourism } \\
\hline Green tourism can ensure the quality of the environment & 3.60 & 0.83 \\
\hline Green tourism can promote the local tourism industry & 3.51 & 0.79 \\
\hline Green tourism has educational meaning & 3.87 & 0.91 \\
\hline Green tourism can enhance my travel experiences & 3.72 & 0.75 \\
\hline Green tourism can enhance my knowledge of resource conservation & 3.77 & 0.83 \\
\hline \multicolumn{3}{|l|}{ Section 5: Influencing factors of willingness of participation in green tourism } \\
\hline \multicolumn{3}{|l|}{ Self-environmental awareness } \\
\hline Learning new ways of environmental conservation & 3.54 & 0.93 \\
\hline Helping with environmental protection & 3.43 & 0.87 \\
\hline Promotion of low carbon tourism & 3.40 & 0.80 \\
\hline Awareness of environmental conservation & 3.33 & 0.95 \\
\hline \multicolumn{3}{|l|}{ Destination green service } \\
\hline Convenient public transportation services & 3.99 & 0.83 \\
\hline Attractive carbon reduction tourism program & 3.91 & 0.89 \\
\hline Prevalence of green hotels & 3.73 & 0.90 \\
\hline Diverse local cultural and features & 3.82 & 0.90 \\
\hline Reasonable travel cost in the destination & 3.85 & 0.96 \\
\hline Experience different types of programs (eliminate due to low factor loading) & 3.65 & 0.83 \\
\hline Escaping from urban areas (eliminate due to low factor loading) & 3.69 & 0.93 \\
\hline
\end{tabular}




\begin{tabular}{lcc}
\hline Professional interpretation & & \\
\hline Skillful low carbon local tour guide & 3.66 & 0.94 \\
Professional low carbon guiding services & 3.80 & 0.88 \\
\hline Section 6: Intention of participation in green tourism & & \\
\hline I will follow green tourism principles when I am traveling & 3.50 & 0.85 \\
\hline Section 7: Environmental responsible tourism behaviors & 3.10 & 1.06 \\
\hline I choose to take public transportation if available & 2.85 & 1.08 \\
I carry my own water bottles when traveling & 2.55 & 0.98 \\
I carry my own shopping bags when traveling & 2.69 & 1.02 \\
I carry my own toothbrush and towels when traveling & 3.33 & 0.85 \\
\hline I choose to purchase souvenirs with less packaging & & \\
\hline
\end{tabular}

\section{References}

1. Becken, S.; Patterson, M. Measuring national carbon dioxide emissions from tourism as a key step towards achieving sustainable tourism. J. Sustain. Tour. 2006, 14, 323-338. [CrossRef]

2. Scott, D.; Peeters, P.; Gössling, S. Can tourism deliver its "aspirational" greenhouse gas emission reduction targets? J. Sustain. Tour. 2010, 18, 393-408. [CrossRef]

3. World Travel and Tourism Council (WTTC). Leading the Challenge on Climate Change; WTTC: London, UK, 2009.

4. Transportation for Transport. Delivering Sustainable Low Carbon Travel: An Essential Guide for Local Authorities; Crown Copyright: London, UK, 2009; ISBN 978-1-84864-040-5.

5. Brög, W.; Erl, E.; Mense, N. Individualised marketing changing travel behaviour for a better environment. Presented at the OECD Workshop: Environmentally Sustainable Transport, Berlin, Germany, 5 June 2002; pp. 3-12.

6. Handy, S.; Cao, X.; Mokhtarian, P. Correlation or causality between the built environment and travel behavior? Evidence from Northern California. Transp. Res. Part D Transp. Environ. 2005, 10, 427-444. [CrossRef]

7. Pingling County Government. Low Carbon Tourism. Available online: http://lowcarbon.epd.ntpc.gov.tw/ dispPageBox/Tpclc/TpcCp.aspx?ddsPageID=TPCLCH11\& (accessed on 14 July 2017).

8. The Green Tourism Association of Taiwan. Available online: https://www.facebook.com/groups/ 117446668294810 /about/ (accessed on 2 June 2018).

9. Chiesa, T.; Gautam, A. Towards a Low Carbon Travel \& Tourism Sector. World Economic Forum Report Prepared with the Support of Booz \& Company. 2009. Available online: http:/ / www.greeningtheblue.org/ sites / default/ files/Towards\%20a\%20low\%20carbon\%20travel\%20\&\%20tourism\%20sector.pdf (accessed on 14 July 2017).

10. Filimonau, V.; Dickinson, J.; Robbins, D.; Huijbregts, M.A. Reviewing the carbon footprint analysis of hotels: Life Cycle Energy Analysis (LCEA) as a holistic method for carbon impact appraisal of tourist accommodation. J. Clean. Prod. 2011, 19, 1917-1930. [CrossRef]

11. Nawijn, J.; Peeters, P.M. Travelling 'green': Is tourists' happiness at stake? Curr. Issues Tour. 2010, 13, 381-392. [CrossRef]

12. Horng, J.-S.; Liaw, Y.-J. Can we enhance low-carbon tour intentions through climate science or responsibility sharing information? Curr. Issues Tour. 2017, 1-25. [CrossRef]

13. Dolnicar, S.; Crouch, G.I.; Long, P. Environment-friendly Tourists: What Do We Really Know about Them? J. Sustain. Tour. 2008, 16, 197-210. [CrossRef]

14. Han, H. Travelers' pro-environmental behavior in a green lodging context: Converging value-belief-norm theory and the theory of planned behavior. Tour. Manag. 2015, 47, 164-177. [CrossRef]

15. Ajzen, I. From intentions to actions: A theory of planned behavior. In Action Control; Springer: Berlin, Germany, 1985; pp. 11-39.

16. Cheng, J.C.-H.; Monroe, M.C. Connection to nature: Children's affective attitudes toward nature. Environ. Behav. 2012, 44, 31-49. [CrossRef] 
17. Hunecke, M.; Blöbaum, A.; Matthies, E.; Höger, R. Responsibility and environment: Ecological norm orientation and external factors in the domain of travel mode choice behavior. Environ. Behav. 2001, 33, 830-852. [CrossRef]

18. Titze, S.; Stronegger, W.J.; Janschitz, S.; Oja, P. Association of built-environment, social-environment and personal factors with bicycling as a mode of transportation among Austrian city dwellers. Prev. Med. 2008, 47, 252-259. [CrossRef] [PubMed]

19. Dann, G.M. Tourist motivation an appraisal. Ann. Tour. Res. 1981, 8, 187-219. [CrossRef]

20. Uysal, M.; Hagan, L.A.R. Motivation of pleasure travel and tourism. Encycl. Hosp. Tour. 1993, $21,798-810$.

21. Kasser, T.; Ryan, R.M. Further examining the American dream: Differential correlates of intrinsic and extrinsic goals. Personal. Soc. Psychol. Bull. 1996, 22, 280-287. [CrossRef]

22. Tabernero, C.; Hernández, B. Self-efficacy and intrinsic motivation guiding environmental behavior. Environ. Behav. 2011, 43, 658-675. [CrossRef]

23. Chow, A.S.Y.; Cheng, I.N.Y.; Cheung, L.T.O. Self-determined travel motivations and ecologically responsible attitudes of nature-based visitors to the Ramsar wetland in South China. Ann. Leisure Res. 2017, 25, 1-20. [CrossRef]

24. De Young, R. New Ways to Promote Proenvironmental Behavior: Expanding and Evaluating Motives for Environmentally Responsible Behavior. J. Soc. Issues 2000, 56, 509-526. [CrossRef]

25. Deci, E.L.; Ryan, R.M. The "What" and "Why" of Goal Pursuits: Human Needs and the Self-Determination of Behavior. Psychol. Inq. 2000, 11, 227-268. [CrossRef]

26. Boerschig, S.; De Young, R. Evaluation of Selected Recycling Curricula: Educating the Green citizen. J. Environ. Educ. 1993, 24, 17-22. [CrossRef]

27. Frick, J.; Kaiser, F.G.; Wilson, M. Environmental knowledge and conservation behavior: Exploring prevalence and structure in a representative sample. Personal. Individ. Differ. 2004, 37, 1597-1613. [CrossRef]

28. Kollmuss, A.; Agyeman, J. Mind the Gap: Why do people act environmentally and what are the barriers to pro-environmental behavior? Environ. Educ. Res. 2002, 8, 239-260. [CrossRef]

29. Boubonari, T.; Markos, A.; Kevrekidis, T. Greek Pre-Service Teachers' Knowledge, Attitudes, and Environmental Behavior toward Marine Pollution. J. Environ. Educ. 2013, 44, 232-251. [CrossRef]

30. Carmi, N.; Arnon, S.; Orion, N. Transforming Environmental Knowledge into Behavior: The Mediating Role of Environmental Emotions. J. Environ. Educ. 2015, 46, 183-201. [CrossRef]

31. Kaplan, S. New ways to promote proenvironmental behavior: Human nature and environmentally responsible behavior. J. Soc. Issues 2000, 56, 491-508. [CrossRef]

32. Schultz, P. New environmental theories: Empathizing with nature: The effects of Perspective taking on concern for environmental issues. J. Soc. Issues 2000, 56, 391-406. [CrossRef]

33. Stern, P.C. New environmental theories: Toward a coherent theory of environmentally significant behavior. J. Soc. Issues 2000, 56, 407-424. [CrossRef]

34. Stern, P.C.; Dietz, T. The value basis of environmental concern. J. Soc. Issues 1994, 50, 65-84. [CrossRef]

35. Schwartz, S.H. Normative influences on altruism1. In Advances in Experimental Social Psychology; Elsevier: New York, NY, USA, 1977; Volume 10, pp. 221-279.

36. Eagly, A.H.; Chaiken, S. The Psychology of Attitudes; Harcourt Brace Jovanovich College Publishers: San Diego, CA, USA, 1993.

37. Hultman, M.; Kazeminia, A.; Ghasemi, V. Intention to visit and willingness to pay premium for ecotourism: The impact of attitude, materialism, and motivation. J. Bus. Res. 2015, 68, 1854-1861. [CrossRef]

38. Shin, Y.H.; Moon, H.; Jung, S.E.; Severt, K. The effect of environmental values and attitudes on consumer willingness to pay more for organic menus: A value-attitude-behavior approach. J. Hosp. Tour. Manag. 2017, 33, 113-121. [CrossRef]

39. Wood, R.; Bandura, A. Impact of conceptions of ability on self-regulatory mechanisms and complex decision making. J. Personal. Soc. Psychol. 1989, 56, 407-415. [CrossRef]

40. Lee, T.H.; Jan, F.-H. The effects of recreation experience, environmental attitude, and biospheric value on the environmentally responsible behavior of nature-based tourists. Environ. Manag. 2015, 56, 193-208. [CrossRef] [PubMed]

41. Strauss, A.; Corbin, J. Basics of Qualitative Research: Procedures and Techniques for Developing Grounded Theory; Sage: Thousand Oaks, CA, USA, 1998. 
42. Larsen, G.R.; Guiver, J.W. Understanding tourists' perceptions of distance: A key to reducing the environmental impacts of tourism mobility. J. Sustain. Tour. 2013, 21, 968-981. [CrossRef]

43. Environmental Protection Agency. Low Carbon Sustainable Home Information Network. Available online: https:/ / lcss.epa.gov.tw/LcssOldData/Default.aspx?Action=EBB53A55B1BBAF77 (accessed on 14 July 2015).

44. Chen, J.S.; Hsu, C.H. Developing and validating a riverboat gaming impact scale. Ann. Tour. Res. 2001, 28, 459-476. [CrossRef]

45. O’Leary-Kelly, S.W.; Vokurka, R.J. The empirical assessment of construct validity. J. Oper. Manag. 1998, 16, 387-405. [CrossRef]

46. Fornell, C.; Larcker, D.F. Evaluating structural equation models with unobservable variables and measurement error. J. Mark. Res. 1981, 39-50. [CrossRef]

47. Lee, T.H.; Jan, F.-H. Ecotourism Behavior of Nature-Based Tourists: An Integrative Framework. J. Travel Res. 2017, 0047287517717350. [CrossRef]

48. Cheung, L.T.; Chow, A.S.; Fok, L.; Yu, K.-M.; Chou, K.-L. The effect of self-determined motivation on household energy consumption behaviour in a metropolitan area in southern China. Energy Effic. 2017, 10, 549-561. [CrossRef]

49. Webb, D.; Soutar, G.N.; Mazzarol, T.; Saldaris, P. Self-determination theory and consumer behavioural change: Evidence from a household energy-saving behaviour study. J. Environ. Psychol. 2013, 35, 59-66. [CrossRef]

(C) 2018 by the authors. Licensee MDPI, Basel, Switzerland. This article is an open access article distributed under the terms and conditions of the Creative Commons Attribution (CC BY) license (http:/ / creativecommons.org/licenses/by/4.0/). 